ARTICLE

Received 10 Aug 2014 | Accepted 28 Jan 2015 | Published 2 Mar $2015 \quad$ DOl: 10.1038/ncomms7430

\title{
Ultrathin platinum nanowires grown on single-layered nickel hydroxide with high hydrogen evolution activity
}

Huajie Yin ${ }^{1,2}$, Shenlong Zhao ${ }^{1}$, Kun Zhao ${ }^{1}$, Abdul Muqsit ${ }^{1}$, Hongjie Tang${ }^{1}$, Lin Chang ${ }^{1}$, Huijun Zhao ${ }^{3}$, Yan Gao ${ }^{1} \&$ Zhiyong Tang ${ }^{1}$

Design and synthesis of effective electrocatalysts for hydrogen evolution reaction in alkaline environments is critical to reduce energy losses in alkaline water electrolysis. Here we report a hybrid nanomaterial comprising of one-dimensional ultrathin platinum nanowires grown on two-dimensional single-layered nickel hydroxide. Judicious surface chemistry to generate the fully exfoliated nickel hydroxide single layers is explored to be the key for controllable growth of ultrathin platinum nanowires with diameters of about $1.8 \mathrm{~nm}$. Impressively, this hybrid nanomaterial exhibits superior electrocatalytic activity for hydrogen evolution reaction in alkaline solution, which outperforms currently reported catalysts, and the obviously improved catalytic stability. We believe that this work may lead towards the development of singlelayered metal hydroxide-based hybrid materials for applications in catalysis and energy conversion.

\footnotetext{
${ }^{1}$ Laboratory for Nanosystem and Hierarchy Fabrication, National Center for Nanoscience and Technology, Beijing 100190, P.R. China. ${ }^{2}$ Department of Chemistry, Tsinghua University, Beijing 100084, P.R. China. ${ }^{3}$ Centre for Clean Environment and Energy, Gold Coast Campus, Griffith University, Queensland 4222, Australia. Correspondence and requests for materials should be addressed to Z.T. (email: zytang@nanoctr.cn).
} 
O utstanding energy storage density and perfect environmental friendliness make hydrogen an ideal energy carrier or clean fuel ${ }^{1,2}$. Among different strategies to produce hydrogen, alkaline water electrolysis has been receiving special attention due to its unique advantages including unlimited reactant availability, good manufacturing safety, stable output and high product purity ${ }^{3-7}$. However, the sluggish kinetics of hydrogen evolution reaction (HER) in a basic environment $\left(2 \mathrm{H}_{2} \mathrm{O}+2 \mathrm{e} \rightarrow \mathrm{H}_{2}+2 \mathrm{OH}^{-}\right)$causes high overpotential and associated large energy consumption, which greatly hinder practical application of alkaline electrolysis ${ }^{8}$. As a typical example, though platinum $(\mathrm{Pt})$ is generally believed as one of the best electrocatalysts for HER, its catalytic activity is about two orders of magnitude lower in alkaline environment compared with that in acidic electrolyte $e^{8-18}$. A plausible way to enhance the HER activity of $\mathrm{Pt}$ in basic media is a combination of $\mathrm{Pt}$ with metal hydroxides, that is, electrochemical deposition of ultrathin $\mathrm{Ni}(\mathrm{OH})_{2}$ nanoclusters on Pt electrode surfaces ${ }^{8,19-23}$. In this type of hybrid materials, the edges of the $\mathrm{Ni}(\mathrm{OH})_{2}$ clusters promote dissociation of water and production of hydrogen intermediates, which subsequently adsorb on the nearby $\mathrm{Pt}$ surfaces and recombine into molecular hydrogen ${ }^{8}$. These pioneering works hold the promise that the sluggish kinetics of HER might be circumvented if rational fabrication of the hybrid materials could be accomplished and the synergetic interactions between noble metal and metal hydroxide are exploited. However, unlike many reports on successful deposition of noble metal nanoparticles (NPs) on 2D graphene oxide (GO) sheets ${ }^{24-27}$, controllable growth of noble metal NPs on the layered metal hydroxide sheets is rarely realized. The difficulty lies in the fact that, with respect to the GO sheets, much fewer surface functional groups (like carboxylic acid and carbonyl) result in the reduced adsorption of noble metal ions onto the metal hydroxide sheets, making it unfavourable for heterogeneous nucleation and growth of noble metal NPs on the surface of the layered metal hydroxides.

In this work, we report a design strategy in which we grow onedimensional (1D) ultrathin $\mathrm{Pt}$ nanowires (NWs) on twodimensional (2D) $\mathrm{Ni}(\mathrm{OH})_{2}$ nanosheets to construct the high performance catalysts for HER in basic solution. We demonstrate that single-layered $\mathrm{Ni}(\mathrm{OH})_{2}\left(\mathrm{SL}-\mathrm{Ni}(\mathrm{OH})_{2}\right)$ nanosheets with the suitable surface modification are the key to immobilization and growth of ultrathin Pt NWs (defined as Pt NWs/SL-Ni(OH) 2 ), and the obtained Pt NWs/SL-Ni(OH $)_{2}$ hybrid materials exhibit unprecedented catalytic activity and stability towards HER in basic solution. Unlike previous reports involving utilization of Pt electrodes ${ }^{8,19-22}$, the selection of single-layered $2 \mathrm{D} \mathrm{Ni}(\mathrm{OH})_{2}$ $\left(\mathrm{SL}-\mathrm{Ni}(\mathrm{OH})_{2}\right)$ nanosheets as the substrates is based on cost considerations $^{28,29}$, as $\mathrm{SL}-\mathrm{Ni}(\mathrm{OH})_{2}$ sheets might be cheaply acquired via exfoliation of lamellar $\alpha-\mathrm{Ni}(\mathrm{OH})_{2}$ (refs 30-33). Furthermore, compared with commonly used zero-dimensional (0D) Pt nanoparticles (NPs), 1D ultrathin Pt NWs of high aspect ratios, few lattice boundaries and smooth crystal planes offer the opportunity for improvement of the catalytic activity ${ }^{34-44}$. Meanwhile, a large contact area between $\mathrm{Pt}$ NWs and the $\mathrm{Ni}(\mathrm{OH})_{2}$ substrates can effectively alleviate possible migration and aggregation of Pt NWs and thus benefit enhancement of the catalytic stability ${ }^{40}$.

\section{Results}

Growth of ultrathin Pt nanowires on single-layered $\mathrm{Ni}(\mathrm{OH})_{2}$. The synthesis procedure of $\mathrm{Pt} \mathrm{NWs} / \mathrm{SL}-\mathrm{Ni}(\mathrm{OH})_{2}$ is schematically depicted in Fig. 1a. First, well-dispersed SL-Ni(OH $)_{2}$ nanosheets in formamide were prepared by exfoliation of layered $\mathrm{Ni}(\mathrm{OH})_{2}$ intercalated with dodecyl sulfate (DS) ions ${ }^{33}$. The single-layered nature of the exfoliated SL-Ni(OH $)_{2}$ nanosheets was confirmed by the corresponding atomic force microscopy (AFM) measurement (Supplementary Fig. 1). Subsequently, $300 \mu \mathrm{K}_{2} \mathrm{PtCl}_{4}(60 \mathrm{mM})$ and $50 \mu \mathrm{l} \mathrm{KOH}(5 \mathrm{M})$ aqueous solutions were added to $10 \mathrm{ml}$ $\mathrm{SL}-\mathrm{Ni}(\mathrm{OH})_{2}$ formamide dispersion $\left(0.5 \mathrm{mg} \mathrm{ml}^{-1}\right)$, respectively. Finally, the mixture was subjected to solvothermal treatment in a 20-ml Teflon-lined autoclave at $120^{\circ} \mathrm{C}$ for $4 \mathrm{~h}$ to obtain the $\mathrm{Pt}$ $\mathrm{NWs} / \mathrm{SL}-\mathrm{Ni}(\mathrm{OH})_{2}$ hybrids. In this synthesis, formamide acts as both the solvent for dispersing $\mathrm{SL}-\mathrm{Ni}(\mathrm{OH})_{2}$ nanosheets and the reducing agent for generation of $\mathrm{Pt} \mathrm{NWs}^{33,45}$. Figure 1b,c presents the typical transmission electron microscopy (TEM) images of as-synthesized products. It is evident that the $\mathrm{Pt}$ nanostructures are exclusively formed on the surface of SL-Ni(OH $)_{2}$ nanosheets, and about $94 \%$ Pt nanostructures are 1D ultrathin NWs with the uniform diameters of $\sim 1.8 \mathrm{~nm}$ and varying lengths of 10 to $50 \mathrm{~nm}$ (Supplementary Fig. 2). We also note that both the $\mathrm{SL}-\mathrm{Ni}(\mathrm{OH})_{2}$ substrates and the immobilized ultrathin Pt NWs are very sensitive to the electron beam during TEM analysis, and many breakages are discerned when exposed to the electron beam (Supplementary Fig. 3). High-resolution TEM image indicates that the ultrathin Pt NWs are composed of multiple crystalline segments with the lengths of 5 to $10 \mathrm{~nm}$ (black arrows in Fig. 1d). The crystallinity characteristics of $\mathrm{Pt}$ NWs are further investigated by X-ray diffraction (XRD) pattern, in which the diffraction peaks can be indexed to (111), (200), (220) and (311) reflections of face centred cubic ( $f c c)$ Pt (JCPDS No. 87-0647), respectively (Fig. 1e). The XRD result also excludes formation of $\mathrm{Pt}-\mathrm{Ni}$ alloy ${ }^{46}$. The $\mathrm{Ni}(\mathrm{OH})_{2}$ - $\mathrm{Pt}$ contact area in $\mathrm{Pt}$ $\mathrm{NWs} / \mathrm{SL}-\mathrm{Ni}(\mathrm{OH})_{2}$ is qualitatively measured by determining the electrochemical surface area (ECSA) of Pt NWs within $\mathrm{Pt} \mathrm{NWs} / \mathrm{SL}-\mathrm{Ni}(\mathrm{OH})_{2}$ and $\mathrm{Pt} \mathrm{NWs}$ completely exposed after removing $\mathrm{SL}-\mathrm{Ni}(\mathrm{OH})_{2}$ (Supplementary Figs 4-6 and Supplementary Note 1). The contacted part of Pt NWs with $\mathrm{SL}-\mathrm{Ni}(\mathrm{OH})_{2}$ deduced from their ECSA result is $\sim 35 \%$, and hence the exposed $\mathrm{Pt}$ atoms account for $\sim 65 \%$.

In addition to the shape and structure, the composition and chemical state of $\mathrm{Pt} \mathrm{NWs} / \mathrm{SL}-\mathrm{Ni}(\mathrm{OH})_{2}$ are recognized by energydispersive X-ray (EDX) spectrum (Fig. 1f) and X-ray photoelectron spectroscopy (XPS) (Fig. 2). The EDX analysis clearly distinguishes $\mathrm{Pt}$ element from $\mathrm{Pt} \mathrm{NWs}$, as well as $\mathrm{O}$ and $\mathrm{Ni}$ elements from SL-Ni(OH)$)_{2}$ nanosheets (Fig. 1f). Interestingly, small amount of $\mathrm{S}$ element is also detected in EDX spectrum, revealing the adsorption of DS ions on the surface of SL-Ni(OH $)_{2}$ sheets. Deconvolution of Pt $4 \mathrm{f}$ XPS doublet $\left(4 \mathrm{f}_{7 / 2}\right.$ and $\left.4 \mathrm{f}_{5 / 2}\right)$ gives rise to two pairs of peaks, corresponding to dominant $\mathrm{Pt}(0)$ atoms (82.9\%, green curves in Fig. 2a) and less amount of surface Pt (II) ions (18.1\%, red curves in Fig. 2a), respectively. Another feature coexisted in $\mathrm{Pt} 4 \mathrm{f}$ region is the presence of $\mathrm{Ni} 3 \mathrm{p}$ peaks

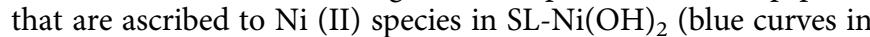
Fig. 2a $)^{47-49}$. It is also discerned by Ni $2 p$ XPS spectra that there is no significant change in the chemical state of $\mathrm{Ni}$ (II) after growing Pt NWs on SL-Ni(OH) $)_{2}$ surfaces (Fig. 2b). This phenomenon is coincident with both TEM and XRD observations (Fig. 1b,c,e), disclosing that $\mathrm{Ni}(\mathrm{OH})_{2}$ nanosheets maintain the lamellar structure and do not react with Pt ions to form the alloy after the solvothermal reaction. The total $\mathrm{Pt}$ content in Pt NWs/SL-Ni(OH) 2 is about 38.0 wt.\%, which is quantitatively measured with a inductively coupled plasma mass spectrometry (ICP-MS) technique.

The experimental parameters including the added amount of $\mathrm{KOH}$, reaction temperature and reaction time were investigated in detail for better understanding of formation mechanism of $\mathrm{Pt}$ $\mathrm{NWs} / \mathrm{SL}-\mathrm{Ni}(\mathrm{OH})_{2}$ hybrid materials. It is found that the reduction rate of Pt precursors by formamide is decreased as the amount of $\mathrm{KOH}$ is increased. In the absence of $\mathrm{KOH}$, large amount of $\mathrm{Pt}$ $\mathrm{NPs}$ is rapidly formed outside the $\mathrm{SL}-\mathrm{Ni}(\mathrm{OH})_{2}$ nanosheets (Supplementary Fig. 7); small amount of adding $\mathrm{KOH}(5 \mu \mathrm{l}$ of 
a
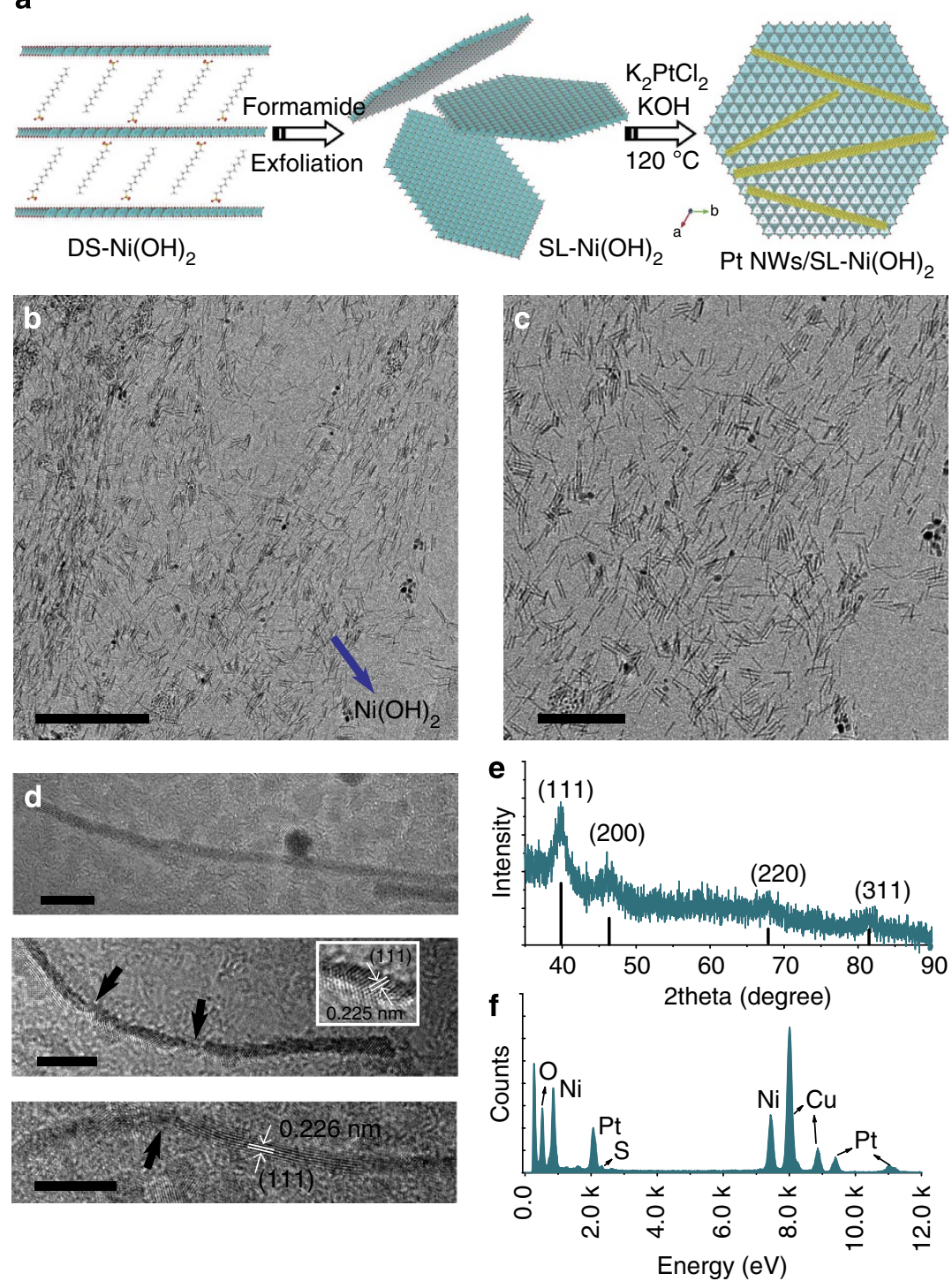

Figure 1 | Schematic illustration of synthesis procedure and the resulting Pt NWs/SL-Ni(OH) 2 . (a) Scheme for synthesis of Pt NWs/SL-Ni(OH) $)_{2}$; (b-d) TEM images of Pt NWs/SL-Ni(OH) $)_{2}$, scale bars in (b), (c) and (d) are 100, 50 and $5 \mathrm{~nm}$, respectively; (e) XRD pattern of Pt NWs/SL-Ni(OH) 2 along with the corresponding JCPDS standard of Pt; (f) EDX spectrum of Pt NWs/SL-Ni(OH) 2 . Note that the Cu signal in (f) originates from the TEM grid used.

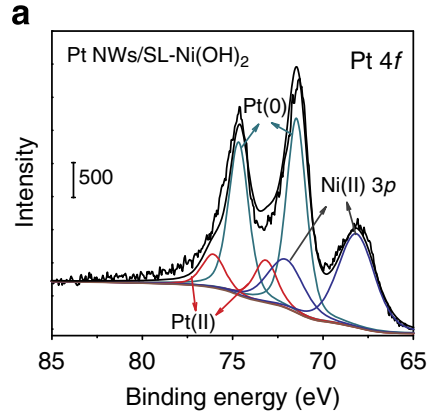

b

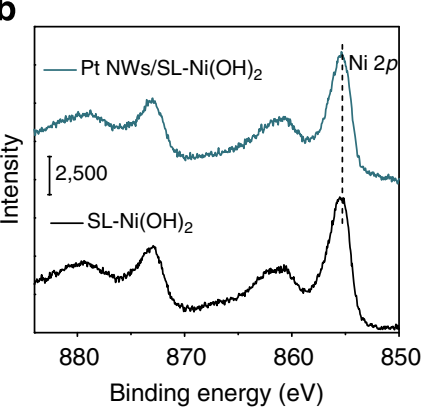

Figure 2 | XPS analysis of Pt NWs/SL-Ni(OH) 2 . (a) XPS spectrum of Pt $4 \mathrm{f}$ region of $\mathrm{Pt} \mathrm{NWs} / \mathrm{SL}-\mathrm{Ni}(\mathrm{OH})_{2}$; (b) XPS spectra of $\mathrm{Ni} 2 \mathrm{p}$ region of Pt NWs/ $\mathrm{SL}-\mathrm{Ni}(\mathrm{OH})_{2}$ and $\mathrm{SL}-\mathrm{Ni}(\mathrm{OH})_{2}$. The dashed line in $(\mathbf{b})$ highlights that the $\mathrm{Ni}$ $2 \mathrm{p}$ peak position in the two samples remains the same.

$5 \mathrm{M} \mathrm{KOH}$ solution into $10 \mathrm{ml}$ of $0.5 \mathrm{mg} \mathrm{ml}^{-1} \mathrm{SL}-\mathrm{Ni}(\mathrm{OH})_{2}$ formamide dispersion) gives rise to production of spherical $\mathrm{Pt}$ NPs with average diameter of $\sim 3.2 \mathrm{~nm}$ on surface of SL-Ni(OH)$)_{2}$
(Pt NPs/SL-Ni(OH) $)_{2}$ ) (Supplementary Fig. 8), whereas the reduction of Pt precursors by formamide is hardly happened even after $12 \mathrm{~h}$ in the presence of excessive amount of $\mathrm{KOH}$ (that is, $100 \mu \mathrm{l}$ of $5 \mathrm{M} \mathrm{KOH}$ solution was added in $10 \mathrm{ml}$ of $0.5 \mathrm{mg} \mathrm{ml}^{-1} \mathrm{SL}-\mathrm{Ni}(\mathrm{OH})_{2}$ formamide dispersion). As shown in Supplementary Fig. 9, the reaction temperature and duration also have large impact on the final products. The aggregates of ultrathin Pt NWs are formed when the reaction time is prolonged from 4 to $12 \mathrm{~h}$ at $120^{\circ} \mathrm{C}$, while Pt NPs assemblies are produced when the reaction temperature is increased from 120 to $140^{\circ} \mathrm{C}$ under $4 \mathrm{~h}$ reaction. This result indicates that the progressive decomposition of SL-Ni(OH $)_{2}$ nanosheets in the formamide occurs during solvothermal reaction, most likely owing to coordination of $\mathrm{N}$ groups of formamide molecules with $\mathrm{Ni}^{2+}$ ions of SL-Ni(OH $)_{2}$ nanosheets. Altogether, the reaction time and temperature should be restricted to avoid decomposition of SL$\mathrm{Ni}(\mathrm{OH})_{2}$ nanosheets, while the added amount of $\mathrm{KOH}$ that determines the reduction rate of $\mathrm{Pt}$ precursors has to be controlled to benefit the heterogeneous growth of 1D Pt NWs on the surfaces of SL-Ni(OH $)_{2}$ nanosheets. 
The presence of DS-stabilized SL-Ni(OH $)_{2}$ nanosheets appears to be another prerequisite for producing the immobilized $\mathrm{Pt}$ NWs. As displayed in Fig. 3a, only spherical Pt NPs with diameters ranging from 1.5 to $3 \mathrm{~nm}$ are prepared in the absence of $\mathrm{SL}-\mathrm{Ni}(\mathrm{OH})_{2}$ sheets. Furthermore, both DS-intercalated $\mathrm{Ni}(\mathrm{OH})_{2}$ nanosheets without fully exfoliation (Supplementary Fig. 10) and carbonate $\left(\mathrm{CO}_{3}^{2-}\right)$-intercalated $\mathrm{Ni}(\mathrm{OH})_{2}$ multilayered nanosheets (Supplementary Fig. 11) are prepared as the contrast substrates to compare with SL-Ni(OH $)_{2}$ nanosheets. It is evident that as for DS-intercalated $\mathrm{Ni}(\mathrm{OH})_{2}$ nanosheets without fully exfoliation, $\mathrm{Pt}$ $\mathrm{NP}$ aggregates are produced and separated from the $\mathrm{Ni}(\mathrm{OH})_{2}$ nanosheets (Fig. 3b); while larger amount of Pt NPs with the diameters of around $5 \mathrm{~nm}$ are grown on the surfaces of $\mathrm{CO}_{3}^{2-}$ intercalated $\mathrm{Ni}(\mathrm{OH})_{2}$ multilayered nanosheets (Supplementary Fig. 12). On the basis of the above results from the control experiments, we deduce that $\mathrm{SL}-\mathrm{Ni}(\mathrm{OH})_{2}$ nanosheets affect the formation of Pt NWs through the following aspects: (1) Unique chemical environment of DS-stabilized SL-Ni(OH $)_{2}$ nanosheets is indispensible for formation of Pt NWs. The high-resolution $\mathrm{N} 1 \mathrm{~s}$ and S $2 p$ XPS spectra (black curves in Fig. 3c,d) of SL-Ni(OH) reveal that both formamide $\left(-\mathrm{CONH}_{2}, 398.8 \mathrm{eV}\right)$ and DS ions $\left(-\mathrm{SO}_{3}^{2-}, 167.7 \mathrm{eV}\right)$ are adsorbed on the $\mathrm{SL}-\mathrm{Ni}(\mathrm{OH})_{2}$ surfaces. Additional $\mathrm{N} 1 \mathrm{~s}$ peak located at $401.5 \mathrm{eV}$ in $\mathrm{SL}-\mathrm{Ni}(\mathrm{OH})_{2}$ corresponds to amide groups of formamide that interact with sulfonic groups in DS ions on the surface of SL-Ni(OH) $)_{2}$ (ref. 50). Meanwhile, this interaction between amide group and sulfonic groups is also recognized in the XPS spectrum of $S 2 p$ region, a peak located at $168.9 \mathrm{eV}$ (ref. 50). After growth of Pt NWs on the surface of $\mathrm{SL}-\mathrm{Ni}(\mathrm{OH})_{2}$ nanosheets, a new peak appears at $399.2 \mathrm{eV}$ that is attributed to the N-Pt bond (green curve in Fig. 3c) ${ }^{24}$. While for S element, the peaks with obviously reduced intensity suggest the replacement of the adsorbed DS ions with $\mathrm{Pt}$ NWs (green curve in Fig. 3d). Evidently, the interaction between formamide molecules with DS ions on the surface of SL-Ni(OH) is crucial for generation of ultrathin $\mathrm{Pt} \mathrm{NWs}^{27,44}$. We also notice that similar phenomenon was found in growth of ultrathin gold nanowires on single-layered graphene oxide (GO) nanosheets, in which the absorbed 1-amino-9-octadecene molecules on GO surfaces guided the anisotropic growth of gold nanowires ${ }^{27}$. In our system, as a comparison, $\mathrm{CO}_{3}^{2-}$-intercalated $\mathrm{Ni}(\mathrm{OH})_{2}$ nanosheets in formamide do not exhibit the corresponding peaks at 401.5 or $168.9 \mathrm{eV}$ (red curves in Fig. 3c,d), suggesting that there is no specific interactions occurring between $\mathrm{CO}_{3}^{2-}$ and formamide. As a result, the $\mathrm{Ni}(\mathrm{OH})_{2}$ nanosheets could not be fully exfoliated by using $\mathrm{CO}_{3}^{2-}$ ions, and only Pt NPs are grown on the surfaces of $\mathrm{CO}_{3}^{2-}$-intercalated multilayered $\mathrm{Ni}(\mathrm{OH})_{2}$ nanosheets (Supplementary Fig. 12). (2) When DS-intercalated $\mathrm{Ni}(\mathrm{OH})_{2}$ nanosheets are exfoliated to single layers, their surface energy will be greatly enhanced, resulting in much stronger adsorption capability towards Pt precursor ions ${ }^{24}$. The increased adsorption ability guarantees heterogeneous nucleation and growth of $\mathrm{Pt}$ on the $\mathrm{SL}-\mathrm{Ni}(\mathrm{OH})_{2}$ nanosheets. (3) Compared with multilayered systems, SL-Ni(OH $)_{2}$ nanosheets, which possess higher defect tolerance ability, could allow for horizontal growth of anisotropic nanostructures through slight adjustment of their crystal structure ${ }^{51}$.
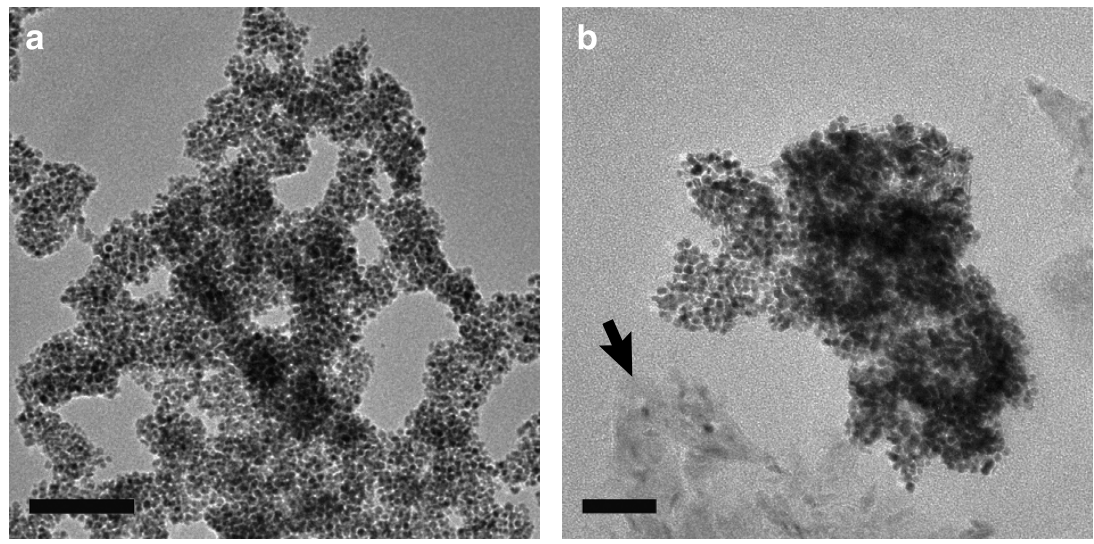

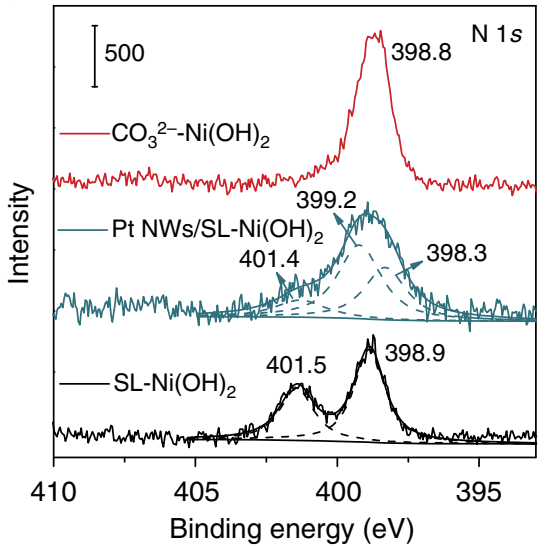

d

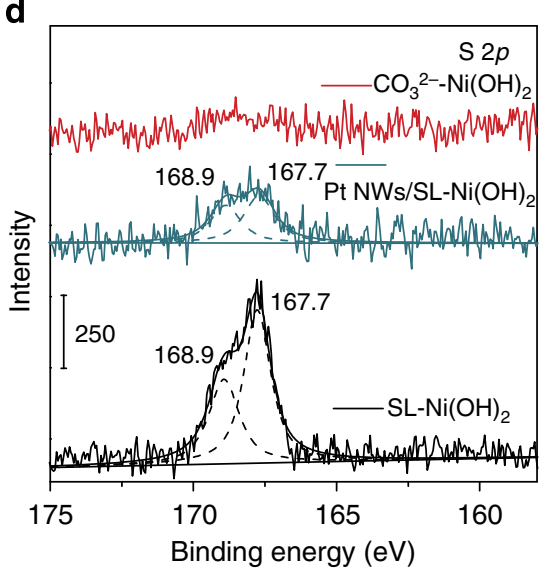

Figure 3 | TEM and XPS analysis of contrast experiments. (a) TEM image of Pt NPs synthesized without SL-Ni(OH) $)_{2} ;(\mathbf{b})$ TEM image of Pt $\mathrm{NPs} / \mathrm{Ni}(\mathrm{OH})_{2}$ synthesized in the presence of DS-intercalated $\mathrm{Ni}(\mathrm{OH})_{2}$ without fully exfoliation, and the black arrow points to $\mathrm{Ni}(\mathrm{OH})_{2}$ sheets; (c,d) XPS spectra of $\mathrm{N} 1 \mathrm{~s}$ and $\mathrm{S} 2 \mathrm{p}$ region of $\mathrm{CO}_{3}^{2}{ }^{-}$-intercalated $\mathrm{Ni}(\mathrm{OH})_{2}, \mathrm{Pt} \mathrm{NWs} / \mathrm{SL}-\mathrm{Ni}(\mathrm{OH})_{2}$ and SL-Ni(OH) 2 . 
a

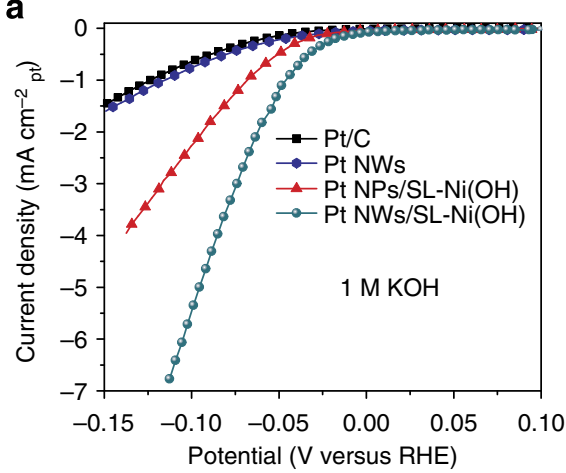

C

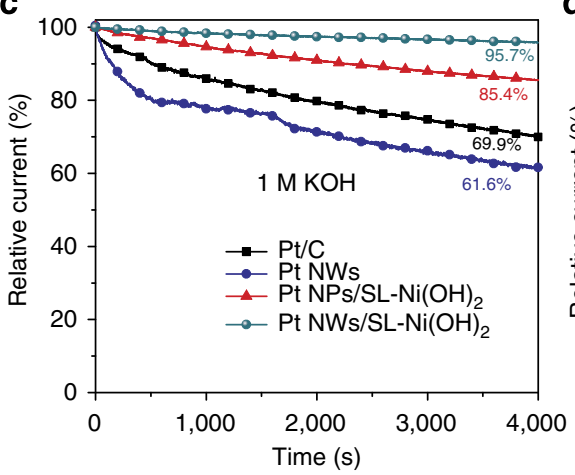

b

d
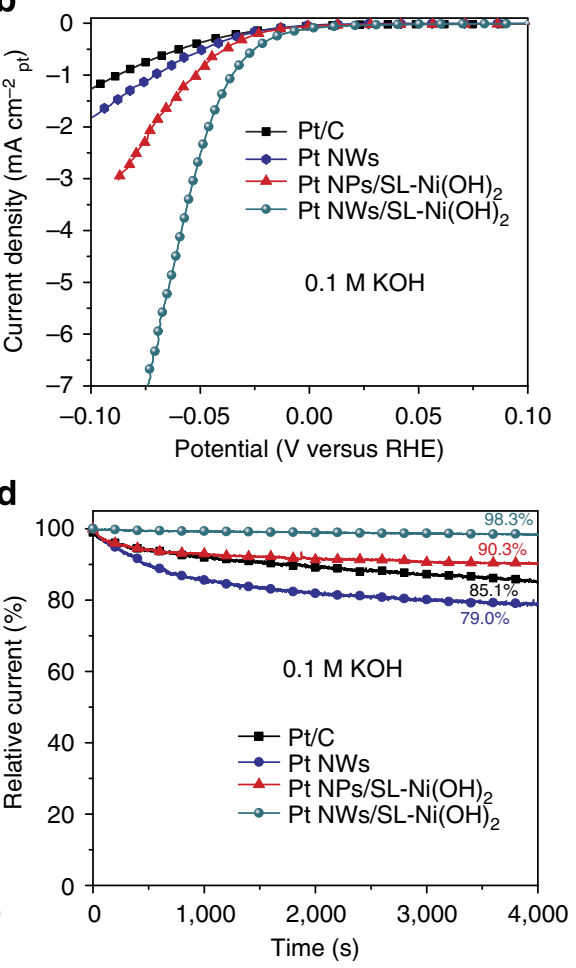

Figure 4 | Electrocatalytic activity and stability of $\mathbf{P t} \mathbf{~ N W s} / \mathbf{S L}-\mathbf{N i}(\mathbf{O H})_{\mathbf{2}}$ hybrid materials. (a) HER activity of Pt NWs/SL-Ni(OH) $2, \mathrm{Pt} \mathrm{NPs} / \mathrm{SL}-\mathrm{Ni}(\mathrm{OH})_{2}$, pure Pt NWs and commercial Pt/C (20 wt\% Pt) in $1 \mathrm{M} \mathrm{KOH}$ at room temperature; (b) HER activity of Pt NWs/SL-Ni(OH) $2, \mathrm{Pt} \mathrm{NPs/SL-Ni(OH)}$, $\mathrm{Pt} N W s$ and commercial Pt/C (20 wt.\%) in $0.1 \mathrm{M} \mathrm{KOH}$ at room temperature. The polarization curves in (a,b) were recorded at a scan rate of $10 \mathrm{mVs}{ }^{-1}$ and a rotation rate of 1,600 r.p.m., and all the current density was normalized by the electrochemical surface areas of Pt. (c) and (d) Normalized current-time (i-t) chronoamperometric responses for $\mathrm{HER}$ at Pt NWs/SL-Ni(OH) 2 , Pt NPs/SL-Ni(OH) 2 Pt NWs and commercial Pt/C (20 wt.\%) electrodes in 1 and $0.1 \mathrm{M} \mathrm{KOH}$ solution.

Electrocatalytic performance of $\mathrm{Pt} \mathrm{NWs} / \mathrm{SL}-\mathrm{Ni}(\mathrm{OH})_{2}$. The HER electrocatalytic activity of as-synthesized Pt NWs/SL-Ni(OH $)_{2}$ is evaluated using a rotating disc electrode in $1 \mathrm{M} \mathrm{KOH}$ solution at a scan rate of $10 \mathrm{mV} \mathrm{s}^{-1}$ with a rotation rate of 1,600 r.p.m. at room temperature (Fig. 4a,b). As comparison, the electrocatalytic activities of other typical nanocatalysts including commercial Pt catalyst (Johnson Matthey, $20 \mathrm{wt} . \% \mathrm{Pt}$ on activated carbon, referred to Pt/C), Pt NPs/SL-Ni(OH) $)_{2}$ (Supplementary Fig. 8) and pure ultrathin $\mathrm{Pt}$ NWs were also investigated at the same conditions. Pure ultrathin $\mathrm{Pt} \mathrm{NWs}$ with average diameter of $\sim 2.0 \mathrm{~nm}$ (Supplementary Fig. 13) were prepared by using $\mathrm{N}$, $\mathrm{N}$-dimethylmethanamide as both reductant and solvent ${ }^{44}$. Seen from Fig. 4a, it is clear that the HER current density normalized by ECSA of $\mathrm{Pt}$ species (for example, $-0.07 \mathrm{~V}$ versus reversible hydrogen electrode (RHE)) at $\mathrm{Pt}$ NWs/SL-Ni(OH) $\left(2.48 \mathrm{~mA} \mathrm{~cm}^{-2}\right)$ is much higher than that at $\mathrm{Pt} \mathrm{NPs} / \mathrm{SL}-$ $\mathrm{Ni}(\mathrm{OH})_{2}\left(1.06 \mathrm{~mA} \mathrm{~cm}^{-2}\right)$, commercial $\mathrm{Pt} / \mathrm{C}\left(0.296 \mathrm{~mA} \mathrm{~cm}^{-2}\right)$ and pure Pt NWs $\left(0.381 \mathrm{~mA} \mathrm{~cm}^{-2}\right)$. Interestingly enough, the HER activity of $\mathrm{Pt} \mathrm{NWs} / \mathrm{SL}-\mathrm{Ni}(\mathrm{OH})_{2}$ is almost one order of magnitude higher than that of the commercial $\mathrm{Pt} / \mathrm{C}$ catalyst. Even for the $\mathrm{Pt} / \mathrm{C}$ catalyst modified by electrochemically deposited $\mathrm{Ni}(\mathrm{OH})_{2}\left(\mathrm{Pt} / \mathrm{C} @ \mathrm{Ni}(\mathrm{OH})_{2}\right)$, the HER activity $\left(0.692 \mathrm{~mA} \mathrm{~cm}^{-2}\right.$ at $-0.07 \mathrm{~V}$ versus RHE) is still far below that of Pt NWs/SL$\mathrm{Ni}(\mathrm{OH})_{2}$ (Supplementary Fig. 14). In addition, HER electrocatalytic activity in less alkaline condition $(0.1 \mathrm{M} \mathrm{KOH})$ is investigated (Fig. 4b), and remarkably the HER current density at $\mathrm{Pt} \mathrm{NWs} / \mathrm{SL}-\mathrm{Ni}(\mathrm{OH})_{2}\left(6.31 \mathrm{~mA} \mathrm{~cm}^{-2}\right.$ at $-0.07 \mathrm{~V}$ versus RHE) is also much higher than that at $\mathrm{Pt} \mathrm{NPs} / \mathrm{SL}-\mathrm{Ni}(\mathrm{OH})_{2}$ $\left(1.86 \mathrm{~mA} \mathrm{~cm}^{-2}\right)$, commercial $\mathrm{Pt} / \mathrm{C}\left(0.662 \mathrm{~mA} \mathrm{~cm}^{-2}\right)$ and pure Pt NWs $\left(0.969 \mathrm{~mA} \mathrm{~cm}^{-2}\right)$. The HER current density normalized by the mass of $\mathrm{Pt}$ species is further demonstrated in
Supplementary Fig. 15. The mass current density (at $-0.07 \mathrm{~V}$ versus RHE) of $\mathrm{Pt} \mathrm{NW} / \mathrm{SL}-\mathrm{Ni}(\mathrm{OH})_{2}$ is $0.679 \mathrm{~mA} \mu \mathrm{g}_{\mathrm{Pt}}^{-1}$ in $1 \mathrm{M}$ $\mathrm{KOH}$ and $1.59 \mathrm{~mA} \mu \mathrm{g}_{\mathrm{Pt}}^{-1}$ in $0.1 \mathrm{M} \mathrm{KOH}$ solution, which is 4.35 and 4.50 times than that of commercial $\mathrm{Pt} / \mathrm{C}$, respectively. It is worth mentioning that to our best knowledge, with respect to the important parameters of HER performance (current density at $-0.07 \mathrm{~V}$ versus RHE and overpotential at $4 \mathrm{~mA} \mathrm{~cm}^{-2}$ ), the Pt NWs/SL-Ni $(\mathrm{OH})_{2}$ hybrids outperform the currently reported electrocatalyst systems (Supplementary Table 1). The reason for the superior HER activity of $\mathrm{Pt} \mathrm{NWs} / \mathrm{SL}-\mathrm{Ni}(\mathrm{OH})_{2}$ in basic condition should be ascribed to two major factors: (i) combination of $\mathrm{Pt}$ with $\mathrm{Ni}(\mathrm{OH})_{2}$ greatly enhances the HER activity of $\mathrm{Pt}$ species (Pt NWs/SL-Ni(OH) 2 versus commercial $\mathrm{Pt} / \mathrm{C}$ and pure $\mathrm{Pt} \mathrm{NWs})$. In the hybrid systems, $\mathrm{Ni}(\mathrm{OH})_{2}$ substrates can effectively activate the $\mathrm{HO}-\mathrm{H}$ bond, which remedy the limited capability of $\mathrm{Pt}$ in water dissociation in basic solution for $\mathrm{HER}^{8,23}$. (ii) Ultrathin $1 \mathrm{D} \mathrm{Pt}$ NWs may expose more active sites while maintaining improved electrons transport characteristics, compared with 0D Pt NPs, Pt NPs/Ni(OH $)_{2}$ and $\mathrm{Pt} / \mathrm{C} @ \mathrm{Ni}(\mathrm{OH})_{2}$ (ref. 38). Smaller charge transfer resistance of Pt NWs/SL-Ni(OH $)_{2}$ confirmed by electrochemical impedance spectroscopy further demonstrates this improved electron transport property in 1D Pt NWs (Supplementary Fig. 16 and Supplementary Note 2).

Finally, the stability of Pt NWs/SL-Ni(OH $)_{2}$, Pt NPs/Ni(OH $)_{2}$, pure $\mathrm{Pt} \mathrm{NWs}$ and commercial $\mathrm{Pt} / \mathrm{C}$ during $\mathrm{HER}$ process is evaluated by using the steady carbon fibre paper (CP) as a working electrode (Supplementary Fig. 17). Impressively, the chronoamperometric study indicates that, under the same conditions, the current density at as-synthesized $\mathrm{Pt} \mathrm{NWs} / \mathrm{SL}$ $\mathrm{Ni}(\mathrm{OH})_{2}$ shows a considerably slower decay than that at $\mathrm{Pt} / \mathrm{C}$, 
pure Pt NWs and Pt NPs/SL-Ni(OH $)_{2}$ both in 1 and $0.1 \mathrm{M} \mathrm{KOH}$ (Fig. 4c,d). Through analysing data shown in Fig. 4c,d, several conclusions can be achieved about the stability performance of Pt NWs/SL-Ni $(\mathrm{OH})_{2}$ catalysts. First of all, on the SL-Ni(OH $)_{2}$ substrates, the ultrathin 1D Pt NWs have higher stability compared with Pt NPs. Pt NWs/SL-Ni(OH) 2 preserves 95.7 and $98.3 \%$ of its initial activity in $1 \mathrm{M}$ and $0.1 \mathrm{M} \mathrm{KOH}$, respectively, after 4,000 s test, while Pt NPs/SL-Ni(OH) $)_{2}$ keeps 85.4 and $90.3 \%$ of the initial activity. The excellent electrochemical stability of $1 D$ nanostructures have been demonstrated by several previous reports ${ }^{35,40,52}$. It is widely accepted that the asymmetry of $1 D$ ultrathin structure can effectively suppress physical ripening and dissolution during long-term application. Second, the SL- $\mathrm{Ni}(\mathrm{OH})_{2}$ nanosheets may greatly enhance the HER stability in basic environment. Without the combination of $\mathrm{SL}-\mathrm{Ni}(\mathrm{OH})_{2}$, pure Pt NWs only maintain 61.6 and $79.0 \%$ of its initiate activity in 1 and $0.1 \mathrm{M} \mathrm{KOH}$ after $4,000 \mathrm{~s}$ test. Third, Pt catalysts in lower concentration of $\mathrm{KOH}$ solution possess higher HER stability. Especially for commercial $\mathrm{Pt} / \mathrm{C}$ and pure $\mathrm{Pt} \mathrm{NWs}$, their normalized current remains about 85.1 and $79.0 \%$ in $0.1 \mathrm{M}$ $\mathrm{KOH}$ after $4,000 \mathrm{~s}$ test, which is much $>69.9$ and $61.6 \%$ in $1 \mathrm{M} \mathrm{KOH}$; whereas, for $\mathrm{Pt} \mathrm{NWs} / \mathrm{SL}-\mathrm{Ni}(\mathrm{OH})_{2}$ and $\mathrm{Pt}$ $\mathrm{NPs} / \mathrm{SL}-\mathrm{Ni}(\mathrm{OH})_{2}$, the corresponding variation is much smaller compared with commercial $\mathrm{Pt} / \mathrm{C}$ and pure $\mathrm{Pt}$ NWs. These differences further confirm that the SL-Ni(OH $)_{2}$ could effectively improve the HER stability of Pt nanostructures in strong basic environment. Moreover, to investigate the long-term HER stability of Pt NWs/SL-Ni(OH) both 1 and $0.1 \mathrm{M} \mathrm{KOH}$. As displayed in Supplementary Fig. 18, $\mathrm{Pt}$ NWs/SL-Ni(OH $)_{2}$ keeps 82.9 and $92.5 \%$ of its initial activity in 1 and $0.1 \mathrm{M} \mathrm{KOH}$ after $40,000 \mathrm{~s}$ test. These data highlight the superior stability of $\mathrm{Pt} \mathrm{NWs} / \mathrm{SL}-\mathrm{Ni}(\mathrm{OH})_{2}$ with respect to commercial Pt/C and pure Pt NWs. Supplementary Fig. 18c,d presents typical TEM images of Pt NWs/SL-Ni(OH $)_{2}$ after 40,000 s test in $1 \mathrm{M} \mathrm{KOH}$. Generally, the Pt NWs maintain their initial 1D ultrathin nanostructures. There also appear some aggregates and shorter Pt NWs, and this morphology change that gives rise to partial loss of initial active centres should be responsible for decrease of the HER activity after long-time electrolysis.

\section{Discussion}

In summary, a facile wet-chemical method is developed to in situ grow ultrathin 1D Pt NWs on single-layered $2 \mathrm{D} \mathrm{Ni(OH})_{2}$ nanosheets. Benefitting from the unique morphological and structural features including high crystallinity, easy charge transport and strong coupling between the immobilized Pt NWs and the $\mathrm{Ni}(\mathrm{OH})_{2}$ nanosheets, the Pt NWs/SL-Ni(OH $)_{2}$ hybrid materials exhibit the record high electrocatalytic activity for HER in alkaline solution, which is 4-5 times higher than the commercial $\mathrm{Pt} / \mathrm{C}$ catalyst. Such novel hybrid nanoarchitecture with 1D NWs on single-layered 2D nanosheets not only ensures controllable construction of many artificial materials of varied compositions, geometries and arrangement patterns, but also provides great opportunity for production of the exceptional properties and functionalities ${ }^{53-57}$.

\footnotetext{
Methods

Chemicals. $\mathrm{Ni}\left(\mathrm{NO}_{3}\right)_{2} \cdot 6 \mathrm{H}_{2} \mathrm{O}(99.9 \%$, AR grade) was bought from Sinopharm Chemical Reagent. Urea (99.99\%, AR grade) and hexamethylenetetramine (HMT, $99.9 \%$, AR grade) were purchased from Aladdin Reagent. Sodium dodecyl sulfate (SDS, $99.0 \%$, AR grade) and formamide (99.0\%, AR grade) were purchased from Xilong Chemical Regent. $\mathrm{K}_{2} \mathrm{PtCl}_{4}$ (46-47\% Pt, AR grade) and $\mathrm{KOH}$ (99.98\%, AR grade) were bought from Acros Organics. Ultrapure water (Millipore Milli-Q grade) with a resistivity of $18.2 \mathrm{M \omega}$ was used in all the experiments.
}

Synthesis of single-layered $\mathrm{Ni}(\mathrm{OH})_{2}\left(\mathrm{SL}-\mathrm{Ni}(\mathrm{OH})_{2}\right)$. Preparation of $\mathrm{SL}-\mathrm{Ni}(\mathrm{OH})_{2}$ formamide dispersion was based on the reported method with slight modification ${ }^{33}$. First of all, layered $\mathrm{Ni}(\mathrm{OH})_{2}$ intercalated with $\mathrm{DS}$ was synthesized by precipitation of an aqueous solution of $\mathrm{Ni}^{2+}$ and $\mathrm{SDS}$ through hexamethylenetetramine (HMT) hydrolysis. Three aqueous solutions $(0.5 \mathrm{M}$ $\mathrm{Ni}\left(\mathrm{NO}_{3}\right)_{2} \cdot 6 \mathrm{H}_{2} \mathrm{O}, 0.25 \mathrm{M}$ SDS and $1 \mathrm{M}$ HMT solutions) were prepared, and then the $\mathrm{Ni}^{2}+(4 \mathrm{ml})$, SDS $(40 \mathrm{ml})$ and HMT $(12 \mathrm{ml})$ solutions were mixed in a $200 \mathrm{~cm}^{3}$ Teflon vessel with Milli-Q water $(18 \mathrm{~m} \Omega, 44 \mathrm{ml})$. The mixed solution was heated at $120^{\circ} \mathrm{C}$ for $24 \mathrm{~h}$ under airtight condition. After the reaction, the precipitates obtained were centrifuged, washed with water and ethanol, and dried at room temperature (Supplementary Fig. 10 presented their typical SEM and TEM images). The precipitates $(100 \mathrm{mg})$ were mixed with formamide $(50 \mathrm{ml})$ to exfoliate the host layers, and the resulting suspension was ultrasonicated for $12 \mathrm{~h}$. Subsequently, the suspension was centrifuged (2,000 r.p.m.), and the supernatants were used as the SL-Ni(OH $)_{2}$ formamide dispersion. Detailed characterization was shown in Supplementary Fig. 1.

Synthesis of Carbonate $\left(\mathrm{CO}_{3}^{2-}\right)$-intercalated $\mathrm{Ni}(\mathrm{OH})_{2}$ multilayered nanosheets. Carbonate $\left(\mathrm{CO}_{3}^{2-}\right)$-intercalated $\mathrm{Ni}(\mathrm{OH})_{2}$ multilayered nanosheets were synthesized similar to layered $\mathrm{Ni}(\mathrm{OH})_{2}$ intercalated with DS without adding SDS. Although $\mathrm{CO}_{3}^{2-}$-intercalated $\mathrm{Ni}(\mathrm{OH})_{2}$ was hardly exfoliated to single layer, its formamide suspension $\left(2 \mathrm{mg} \mathrm{ml}^{-1}\right)$ was also treated under ultrasonication for $12 \mathrm{~h}$. Supplementary Fig. 11 presented the typical TEM images of $\mathrm{Ni}(\mathrm{OH})_{2}$ multilayered nanosheets.

Synthesis of Pt NWs/SL-Ni(OH) $)_{2}$. Three hundred microlitres of $\mathrm{K}_{2} \mathrm{PtCl}_{4}$ $(60 \mathrm{mM})$ and $50 \mu \mathrm{KOH}(5 \mathrm{M})$ water solution were added to $10 \mathrm{ml} \mathrm{SL}-\mathrm{Ni}(\mathrm{OH})_{2}$ formamide dispersion $\left(0.5 \mathrm{mg} \mathrm{ml}^{-1}\right)$, respectively. After that, the mixture was subjected to solvothermal treatment in a 20 -ml Teflon-lined autoclave at $120^{\circ} \mathrm{C}$ for $4 \mathrm{~h}$ to obtain Pt NWs/SL-Ni(OH $)_{2}$ products.

Synthesis of Pt NPs/SL-Ni(OH) $)_{2}$. Three hundred microlitres of $\mathrm{K}_{2} \mathrm{PtCl}_{4}(60 \mathrm{mM})$ and $5 \mu \mathrm{KOH}(5 \mathrm{M})$ water solution were added to $10 \mathrm{ml} \mathrm{SL}-\mathrm{Ni}(\mathrm{OH})_{2}$ formamide dispersion $\left(0.5 \mathrm{mg} \mathrm{ml}^{-1}\right)$, respectively. After that, the mixture was subjected to solvothermal treatment in a $20-\mathrm{ml}$ Teflon-lined autoclave at $120^{\circ} \mathrm{C}$ for $4 \mathrm{~h}$ to obtain Pt NPs/SL-Ni(OH $)_{2}$ product. The typical TEM images and XPS analysis of as-synthesized Pt NPs/SL-Ni(OH $)_{2}$ were shown in Supplementary Fig. 8, and the Pt content in Pt NPs/SL-Ni(OH $)_{2}$ was quantitatively measured to be about $40.2 \mathrm{wt} . \%$ by an ICP-MS technique.

Synthesis of Pt NPs/Ni(OH) $)_{2}$. Three hundred microlitres of of $\mathrm{K}_{2} \mathrm{PtCl}_{4}(60 \mathrm{mM})$ and $50 \mu \mathrm{KOH}(5 \mathrm{M})$ water solution were added to $10 \mathrm{ml} \mathrm{Ni}(\mathrm{OH})_{2}$ multilayered nanosheets formamide suspension $\left(0.5 \mathrm{mg} \mathrm{ml}^{-1}\right)$, respectively. After that, the mixture was subjected to solvothermal treatment in a $20-\mathrm{ml}$ Teflon-lined autoclave at $120^{\circ} \mathrm{C}$ for $4 \mathrm{~h}$ to prepare $\mathrm{Pt} \mathrm{NPs} / \mathrm{Ni}(\mathrm{OH})_{2}$.

Synthesis of Pure Pt NWs. Pure Pt NWs were prepared according to ref. 44. In brief, $100 \mathrm{mg}$ of $\mathrm{H}_{2} \mathrm{PtCl}_{6}$ solution (8 wt. \%) and $500 \mathrm{mg}$ of $\mathrm{KOH}$ were added to a mixed solution containing $4 \mathrm{ml}$ of ethylene glycol (EG) and $6 \mathrm{ml}$ of $\mathrm{N}$, $\mathrm{N}$-dimethylmethanamide (DMF). After magnetic stirring for $12 \mathrm{~h}$, the resultant homogeneous and transparent solution was transferred into a $25-\mathrm{ml}$ Teflon-lined autoclave. The autoclave was maintained at $170^{\circ} \mathrm{C}$ for $8 \mathrm{~h}$ and then cooled to room temperature. The black products were collected and washed with ethanol and pure water several times before drying at $80^{\circ} \mathrm{C}$ overnight. Typical TEM images of as-synthesized Pt NWs were shown in Supplementary Fig. 13.

Synthesis of Pt/C@Ni(OH $)_{2}$. Electrochemically deposited $\mathrm{Ni}(\mathrm{OH})_{2}$ clusters on $\mathrm{Pt} / \mathrm{C}$ surfaces were prepared according to ref. 8.

Characterization. TEM was performed on a FEI Tecnai G2 F20 electron microscope operated at $200 \mathrm{kV}$, and the surface morphology was observed under a Hitachi S4800 scanning electron microscope (SEM). Powder XRD patterns were recorded on a Panaltical X'Pert-pro MPD X-ray power diffract meter by using $\mathrm{Cu}$ $\mathrm{K} \alpha$ radiation $(\lambda=1.54056 \AA)$. XPS spectra were performed by an ESCALAB $250 \mathrm{Xi}$ XPS system of Thermo Scientific, where the analysis chamber was $1.5 \times 10^{-9} \mathrm{mbar}$ and the X-ray spot was $500 \mu \mathrm{m}$. AFM measurements were implemented by using a Vecco Dimension 3100 SPM system.

Electrochemical measurements. The catalyst dispersion or ink was prepared by mixing certain amount of catalysts in $765 \mu \mathrm{l}$ of water, $200 \mu \mathrm{l}$ of ethanol and $35 \mu \mathrm{l}$ of $5 \mathrm{wt} \%$ Nafion solution followed by ultrasonication for $1 \mathrm{~h}$. For fabrication of the

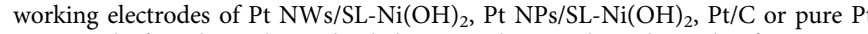
NWs, $5 \mu$ l of catalyst ink was loaded onto a glassy carbon electrode of $5 \mathrm{~mm}$ in diameter. These electrodes were dried at room temperature. To make our tests more rigorous, actual mass concentrations of the Pt species in catalyst inks were determined by ICP-MS, which were $0.820 \mathrm{mg}_{\mathrm{Pt}} \mathrm{ml}^{-1}, 0.686 \mathrm{mg}_{\mathrm{Pt}} \mathrm{ml}^{-1}$, 
$0.856 \mathrm{mg}_{\mathrm{Pt}} \mathrm{ml}^{-1}$ and $0.632 \mathrm{mg}_{\mathrm{Pt}} \mathrm{ml}^{-1}$ in Pt/C, pure Pt NWs, Pt NPs/SL-Ni(OH) and Pt NWs/SL-Ni(OH $)_{2}$, respectively. Therefore, the actual loading amount of $\mathrm{Pt} / \mathrm{C}$, pure Pt NWs, Pt NPs/SL-Ni $(\mathrm{OH})_{2}$ and Pt NWs/SL-Ni $(\mathrm{OH})_{2}$ was $4.10,3.43$, 4.28 and $3.16 \mu \mathrm{g}$, respectively. The accurate measurement of the Pt loading amount was used to determine the ECSA of catalysts and the normalized HER current density by mass of Pt.

The electrochemical tests were performed in a three-electrode electrochemical cell (Pine Instruments) using a Pt wire and a $\mathrm{Ag} / \mathrm{AgCl}$ electrode as a counter and a reference electrode, respectively. Before measurement, a fresh batch of electrolyte with required concentration $(0.1$ or $1 \mathrm{M})$ was prepared in a polypropylene bottle by dissolving the required mass of $\mathrm{KOH}$ in Milli-Q water. Subsequently, $\mathrm{N}_{2}$ gas was purged through the solution to achieve an $\mathrm{O}_{2}$-free condition. The ECSA was obtained by integrating the $\mathrm{H}$-desorption region of Pt species in $0.1 \mathrm{M} \mathrm{KOH}$ and dividing the resulting coulombic charge by $210 \mathrm{C} \mathrm{cm}_{\mathrm{Pt}}^{-2}$ (refs 15,16). All the samples were tested at least for three times to get corresponding average values of ECSA. As shown in Supplementary Fig. 19, the ECSA value of commercial Pt/C, pure Pt NWs, Pt NPs/SL-Ni(OH $)_{2}$ and Pt NWs/SL-Ni(OH $)_{2}$ was $52.5 \pm 2.2$, $40.7 \pm 3.5,27.6 \pm 1.5$ and $22.8 \pm 1.1 \mathrm{~m}^{2} \mathrm{gPt}^{-1}$, respectively.

For HER tests, polarization curves were recorded between -0.2 and $0.2 \mathrm{~V}$ versus RHE at a scan rate of $10 \mathrm{mV} \mathrm{s}^{-1}$ and a rotation rate of 1,600 r.p.m. at rotating disc electrode. The solution resistances of 0.1 and $1 \mathrm{M} \mathrm{KOH}$ measured at room temperature were $44 \Omega$ and $6 \Omega$, respectively. These resistance values were subsequently used for the IR-correction of the potential recorded in the HER polarization experiments.

For stability test, we built an experimental device using $\mathrm{CP}$ as a working electrode (shown in Supplementary Fig. 17). For our stability tests, CP was cut into $1 \times 1 \mathrm{~cm}^{2}$ plate, and then $25 \mu \mathrm{l}$ catalyst ink was dropped on it and completely dried at room temperature. The stability of commercial $\mathrm{Pt} / \mathrm{C}$, pure $\mathrm{Pt} \mathrm{NWs}$, Pt NPs/SL-Ni(OH $)_{2}$ and Pt NWs/SL-Ni(OH $)_{2}$ during HER process was evaluated by a chronoamperometric method both in $1 \mathrm{M} \mathrm{KOH}$ solution (applied potential was $-0.077 \mathrm{~V}$ versus $\mathrm{RHE}$ ) and $0.1 \mathrm{M} \mathrm{KOH}$ (applied potential was $-0.086 \mathrm{~V}$ versus RHE).

\section{References}

1. Dresselhaus, M. S. \& Thomas, I. L. Alternative energy technologies. Nature 414, 332-337 (2001).

2. Gu, S., Xu, B. \& Yan, Y. Electrochemical energy engineering: a new frontier of chemical engineering innovation. Annu. Rev. Chem. Biomol. Eng. 5, 429-454 (2014).

3. Gandía, L. M., Oroz, R., Ursúa, A., Sanchis, P. \& Diéguez, P. M. Renewable hydrogen production: performance of an alkaline water electrolyzer working under emulated wind conditions. Energy Fuels 21, 1699-1706 (2007).

4. Zeng, K. \& Zhang, D. Recent progress in alkaline water electrolysis for hydrogen production and applications. Prog. Energy Combust. Sci. 36, 307-326 (2010).

5. Abbasi, T. \& Abbasi, S. A. 'Renewable' hydrogen: prospects and challenges. Renew. Sust. Energy Rev. 15, 3034-3040 (2011).

6. Kong, D., Wang, H., Lu, Z. \& Cui, Y. $\mathrm{CoSe}_{2}$ nanoparticles grown on carbon fiber paper: an efficient and stable electrocatalyst for hydrogen evolution reaction. J. Am. Chem. Soc. 136, 4897-4900 (2014).

7. Zheng, Y. et al. Toward design of synergistically active carbon-based catalysts for electrocatalytic hydrogen evolution. ACS Nano 8, 5290-5296 (2014).

8. Subbaraman, R. et al. Enhancing hydrogen evolution activity in water splitting by tailoring $\mathrm{Li}^{+}-\mathrm{Ni}(\mathrm{OH})_{2}-\mathrm{Pt}$ interfaces. Science 334, 1256-1260 (2011).

9. Barber, J. H. \& Conway, B. E. Structural specificity of the kinetics of the hydrogen evolution reaction on the low-index surfaces of Pt single-crystal electrodes in $0.5 \mathrm{M} \mathrm{dm}^{-3} \mathrm{NaOH}$. J. Electroanal. Chem. 461, 80-89 (1999).

10. Conway, B. E. \& Tilak, B. V. Interfacial processes involving electrocatalytic evolution and oxidation of $\mathrm{H}_{2}$, and the role of chemisorbed H. Electrochim. Acta 47, 3571-3594 (2002).

11. Marković, N. M., Sarraf, S. T., Gasteiger, H. A. \& Ross, Jr P. Hydrogen electrochemistry on platinum low-index single-crystal surfaces in alkaline solution. J. Chem. Soc. Faraday Trans. 92, 3719-3725 (1996).

12. Marković, N. M., Grgur, B. N. \& Ross, P. N. Temperature-dependent hydrogen electrochemistry on platinum low-index single-crystal surfaces in acid solutions. J. Phys. Chem. B 101, 5405-5413 (1997).

13. Schmidt, T. J., Ross, Jr. P. N. \& Marković, N. M. Temperature dependent surface electrochemistry on Pt single crystals in alkaline electrolytes: Part 2. The hydrogen evolution/oxidation reaction. J. Electroanal. Chem. 524-525, 252-260 (2002).

14. Subbaraman, R. et al. Origin of anomalous activities for electrocatalysts in alkaline electrolytes. J. Phys. Chem. C 116, 22231-22237 (2012).

15. Sheng, W., Gasteiger, H. A. \& Shao-Horn, Y. Hydrogen oxidation and evolution reaction kinetics on platinum: acid $v s$ alkaline electrolytes. J. Electrochem. Soc. 157, B1529-B1536 (2010).

16. Rheinländer, P., Henning, S., Herranz, J. \& Gasteiger, H. A. Comparing hydrogen oxidation and evolution reaction kinetics on polycrystalline platinum in $0.1 \mathrm{M}$ and $1 \mathrm{M} \mathrm{KOH}$. ECS Trans. 50, 2163-2174 (2013).
17. Durst, J. et al. New insights into the electrochemical hydrogen oxidation and evolution reaction mechanism. Energy Environ. Sci. 7, 2255-2260 (2014).

18. Sheng, W., Myint, M., Chen, J. G. \& Yan, Y. Correlating the hydrogen evolution reaction activity in alkaline electrolytes with the hydrogen binding energy on monometallic surfaces. Energy Environ. Sci. 6, 1509-1512 (2013).

19. Subbaraman, R. et al. Trends in activity for the water electrolyser reactions on 3d M(Ni,Co,Fe,Mn) hydr(oxy)oxide catalysts. Nat. Mater. 11, 550-557 (2012).

20. Danilovic, N. et al. Enhancing the alkaline hydrogen evolution reaction activity through the bifunctionality of $\mathrm{Ni}(\mathrm{OH})_{2} /$ metal catalysts. Angew. Chem. 124, 12663-12666 (2012).

21. Strmcnik, D. et al. Improving the hydrogen oxidation reaction rate by promotion of hydroxyl adsorption. Nat. Chem. 5, 300-306 (2013).

22. Danilovic, N. et al. The effect of noncovalent interactions on the HOR, ORR, and HER on $\mathrm{Ru}$, Ir, and $\mathrm{Ru}_{0.50} \mathrm{Ir}_{0.50}$ metal surfaces in alkaline environments. Electrocatal. 3, 221-229 (2012).

23. Chen, C. et al. Highly crystalline multimetallic nanoframes with threedimensional electrocatalytic surfaces. Science 343, 1339-1343 (2014).

24. Yin, H., Tang, H., Wang, D., Gao, Y. \& Tang, Z. Facile synthesis of surfactantfree Au cluster/graphene hybrids for high-performance oxygen reduction reaction. ACS Nano 6, 8288-8297 (2012).

25. Tang, H. et al. Molecular architecture of cobalt porphyrin multilayers on reduced graphene oxide sheets for high-performance oxygen reduction reaction. Angew. Chem. Inter. Ed. 52, 5585-5589 (2013).

26. Yin, H. et al. Three-dimensional graphene/metal oxide nanoparticle hybrids for high-performance capacitive deionization of saline water. Adv. Mater. 25, 6270-6276 (2013).

27. Huang, X. et al. Graphene oxide-templated synthesis of ultrathin or tadpoleshaped Au nanowires with alternating hcp and fcc domains. Adv. Mater. 24, 979-983 (2012).

28. Evans, D. G. \& Slade, R. C. T. Structural aspects of layered double hydroxides. Struct. Bond 119, 1-87 (2006).

29. He, S., An, Z., Wei, M., Evans, D. G. \& Duan, X. Layered double hydroxidebased catalysts: nanostructure design and catalytic performance. Chem. Commun. 49, 5912-5920 (2013).

30. Liu, Z., Ma, R., Osada, M., Takada, K. \& Sasaki, T. Selective and controlled synthesis of $\alpha$ - and $\beta$-cobalt hydroxides in highly developed hexagonal platelets. J. Am. Chem. Soc. 17, 13869-13874 (2005).

31. Ma, R., Liu, Z., Li, L., Iyi, N. \& Sasaki, T. Exfoliating layered double hydroxides in formamide: a method to obtain positively charged nanosheets. J. Mater. Chem. 16, 3809-3813 (2006).

32. Ma, R., Liang, J., Liu, X. \& Sasaki, T. General insights into structural evolution of layered double hydroxide: underlying aspects in topochemical transformation from brucite to layered double hydroxide. J. Am. Chem. Soc. 134, 19915-19921 (2012).

33. Ida, S., Shiga, D., Koinuma, M. \& Matasumto, Y. Synthesis of hexagonal nickel hydroxide nanosheets by exfoliation of layered nickel hydroxide intercalated with dodecyl sulfate ions. J. Am. Chem. Soc. 130, 14038-14039 (2008).

34. Cademartiri, L. \& Ozin, G. A. Ultrathin nanowires: a materials chemistry perspective. Adv. Mater. 21, 1013-1020 (2009).

35. Koenigsmann, C. \& Wong, S. S. One-dimensional noble metal electrocatalysts: a promising structural paradigm for direct methanol fuel cells. Energy Environ. Sci. 4, 1161-1176 (2011).

36. Hu, S. \& Wang, X. Ultrathin nanostructures: smaller size with new phenomena Chem. Soc. Rev. 42, 5577-5594 (2013).

37. Teng, X., Han, W.-Q., Ku, W. \& Hücker, M. Synthesis of ultrathin palladium and platinum nanowires and a study of their magnetic properties. Angew. Chem. 120, 2085-2088 (2008).

38. Koenigsmann, C., Zhou, W., Adzic, R. R., Sutter, E. \& Wong, S. S. Sizedependent enhancement of electrocatalytic performance in relatively defectfree, processed ultrathin platinum nanowires. Nano Lett. 10, 2806-2811 (2010).

39. Song, Y. et al. Synthesis of platinum nanowire networks using a soft template. Nano Lett. 7, 3650-3655 (2007).

40. Ru, L. et al. Biomimetic synthesis of an ultrathin platinum nanowire network with a high twin density for enhanced electrocatalytic activity and durability. Angew. Chem. Int. Ed. 52, 12577-12581 (2013).

41. Sun, S., Jaouen, F. \& Dodelet, J.-P. Controlled growth of Pt nanowires on carbon nanospheres and their enhanced performance as electrocatalysts in PEM fuel cells. Adv. Mater. 20, 3900-3904 (2008).

42. Zhang, L., Li, N., Gao, F., Hou, L. \& Xu, Z. Insulin amyloid fibrils: an excellent platform for controlled synthesis of ultrathin superlong platinum nanowires with high electrocatalytic activity. J. Am. Chem. Soc. 134, 11326-11329 (2012).

43. Xiao, Q., Cai, M., Balogh, M. P., Tessema, M. M. \& Lu, Y. Symmetric growth of Pt ultrathin nanowires from dumbbell nuclei for use as oxygen reduction catalysts. Nano Res. 5, 145-151 (2012).

44. Xia, B. Y., Wu, H. B., Yan, Y., Lou, X. W. \& Wang, X. Ultrathin and ultralong single-crystal platinum nanowire assemblies with highly stable electrocatalytic activity. J. Am. Chem. Soc. 135, 9480-9485 (2013). 
45. Xu, B., Zhang, Z. \& Wang, X. Formamide: an efficient solvent to synthesize water-soluble and sub-ten-nanometer nanocrystals. Nanoscale 5, 4495-4505 (2013).

46. Wu, J., Gross, A. \& Yang, H. Shape and composition-controlled platinum alloy nanocrystals using carbon monoxide as reducing agent. Nano Lett. 11, 798-802 (2011).

47. Mclntyre, N. S. \& Cook, M. G. X-ray photoelectron studies on some oxides and hydroxides of cobalt, nickel, and copper. Anal. Chem. 47, 2208-2213 (1975).

48. Choi, S.-I. et al. Synthesis and characterization of $9 \mathrm{~nm}$ Pt-Ni octahedral with a record high activity of $3.3 \mathrm{~A} / \mathrm{mg}_{\mathrm{Pt}}$ for the oxygen reduction reaction. Nano Lett. 13, 3420-3425 (2013).

49. Park, K.-W. et al. Chemical and electronic effects of $\mathrm{Ni}$ in $\mathrm{Pt} / \mathrm{Ni}$ and $\mathrm{Pt} / \mathrm{Ru} / \mathrm{Ni}$ alloy nanoparticles in methanol electrooxidation. J. Phys. Chem. B 106, 1869-1877 (2002).

50. Wagner, C. D., Riggs, W. M., Davis, L. E. \& Moulder, J. F. Handbook of $X$-ray Photoelectron Spectroscopy 40-41 (Perkin-Elmer Corporation, MN, USA, 1979).

51. Huang, X. et al. Solution-phase epitaxial growth of noble metal nanostructures on dispersible single-layer molybdenum disulfide nanosheets. Nat. Commun. 4, 1444 (2013).

52. Chen, Z., Waje, M., Li, W. \& Yan, Y. Supportless Pt and PtPd nanotubes as electrocatalysts for oxygen-reduction reactions. Angew. Chem. Int. Ed. 46, 4050-4063 (2007).

53. Chen, G. et al. Interfacial effects in iron-nickel hydroxide-platinum nanoparticles enhance catalytic oxidation. Science 344, 495-499 (2014).

54. Huang, X., Qi, X., Boey, F. \& Zhang, H. Graphene-based composites. Chem. Soc. Rev. 41, 666-686 (2012).

55. Huang, X. et al. Synthesis of hexagonal close-packed gold nanostructures. Nat. Commun. 2, 292 (2011).
56. Huang, X. et al. Reduced graphene oxide-templated photochemical synthesis and in situ assembly of Au nanodots to orderly patterned Au nanodots chains. Small 6, 513-516 (2010).

57. Zhao, Y., Chen, G., Zheng, N. \& Fu, G. Mechanisms for CO oxidation on Fe(III)-OH-Pt interface: a DFT study. Faraday Discuss. doi:10.1039/ C4FD00144C (2014)

\section{Acknowledgements}

This work was supported financially by National Research Fund for Fundamental Key Project (2014CB931801) and National Natural Science Foundation of China (21025310)

\section{Author contributions}

Z.T. proposed the research direction and guided the project. H.Y. and S.Z. designed and performed the experiments. Z.T. and H.Y. analysed and discussed the experimental results and drafted the manuscript. K.Z., A.M., H.T., L.C., H.Z. and Y.G. joined the discussion of data and gave useful suggestions.

\section{Additional information}

Supplementary information accompanies this paper at http://www.nature.com/ naturecommunications.

Competing financial interests: The authors declare no competing financial interests.

Reprints and permission information is available online at http://npg.nature.com/ reprintsandpermissions.

How to cite this article: Yin, H. et al. Ultrathin platinum nanowires grown on single-layered nickel hydroxide with high hydrogen evolution activity. Nat. Commun. 6:6430 doi: 10.1038/ncomms7430 (2015). 